\title{
Research on Smart Jiujiang by Internet of Things
}

\author{
Ningli Liang \\ Jiujiang University, Jiangxi China \\ LiangnI01@163.com
}

Keywords: Smart City; Cloud Computing; Internet of Things; Large Data

\begin{abstract}
Smart city is a concentrated expression about the urban sustainable development and a new mode of contemporary urban development which providing a more high-efficient and flexible strategic support for urban governance. It is based on the comprehensive application of Internet of Things and the large data. With the centering on the concerns of urban-rural integration development and livelihood core demands, this propose of paper the construction mode of Smart Jiujiang to facilitate the sustainable development, which should have certain practical significance to promote the construction of the future-oriented smart Jiujiang. It will provide the service of a more humanized and convenient innovative application for the common application and the efficient and friendly development for the modern city.
\end{abstract}

\section{Introduction}

In 2015 the "State Council on promoting" Internet plus "action guidance" officially released. As an opportunity, we should dig out and release the productive factors and resource value of information resources. The intelligent urban of IT infrastructure is constructed by collecting and storing the massive information data in real time. As sociation applications through data interworking, exchange, sharing, and business collaboration. In urban construction, the Internet and information technology, new industrialization, urbanization and agricultural modernization should be combined to build a smart city for the future. Smart city is an important way to realize the urban economic transformation, fine management and optimized service.

\section{General Idea of the Idea of Smart Jiujiang}

The Smart Jiujiang overall planning needs to actively implement the national and Jiangxi provinces. Jiujiang city of wisdom "Internet plus", big data, cloud computing and other aspects of the policy requirements. We should give full play to the catalytic role of information technology in deepening reform, improving government governance capability and modernization of the governance system and strengthening supply reform.

The wisdom of Jiujiang overall planning needs on the strategy and the "13th 5Year Plan" of Jiujiang economic and social development strategy of convergence. "Wisdom Jiujiang" overall planning needs to be based on the government level to promote the urban informatization, infrastructure layout, information resources sharing, information application, intensive collaboration. We should pay attention to the public demand for information technology, and advocate and lead the quality life in the information age.

\section{Construction objectives}

The basic network is reliable. The application and support of advanced technology can't be separated from the construction of a smart city. It is expected to complete the full coverage of the city's all optical network by 2020. Fiber broadband home popularity rate of $75 \%$, The two-way conversion rate of CATV network is $90 \%$. Fully built wireless city $4 \mathrm{G}$ and above, the user penetration rate of $90 \%$. 
Build a preliminary and perfect "wisdom Jiujiang" data center. Building a unified data service platform". Form a unified data resource system throughout the city. Establishing the system mechanism of social development and utilization of data. Build complete basic database, subject database and service database.

The public service is convenient. Preliminary construction of the service system of "wisdom Jiujiang" public service platform. Provision of multi inclusive public services applications. To promote education and cultural infrastructure, information resources equalization, networking, community public service information on the city's full coverage of the community.

Befor 2020, Jiujiang will be built a model based on "network information resource planning, ubiquitous and reliable sharing, public management and public service, collaborative, industry innovation efficiency convenient inclusive" as the main feature, competitive domestic smart city.

\section{Construction Phase Steps}

Smart Jiujiang development present situation is based on the Internet of things information.

a. Infrastructure construction needs to be strengthened. Basic broadband network carrying capacity is not strong. $3 \mathrm{G}$ and $4 \mathrm{G}$ network coverage is not wide. WiFi coverage in key sites is incomplete. The coverage capacity of digital radio and television network is insufficient, and the e-government network needs to be further extended to the village (community). Water, electricity, gas, communications and other urban infrastructure, supporting sensors have not yet been integrated.

b. Data resource co-ordination services need to be improved. Cloud computing service capacity is still insufficient. The basic databases, such as macro economy, geographical space, urban resources and credit information are urgently needed to be built.

c. The popularization level of public service needs to be improved. The single public service channel, so that Pratt \& Whitney convenient service applications missing. Further enhance the public sense of well-being and sense of gain.

According to the present situation of Internet of things in our city, we can do the following.

a. initial stage: initial construction has achieved initial success. Comprehensive planning wisdom Jiujiang construction and development roadmap, laying the blueprint for the development of wisdom Jiujiang. Around the city's operations management and industrial support services, the basic project to start the project. Gradually improve the "wisdom Jiujiang" supporting the construction of protection. the construction of the "wisdom Jiujiang" command and management center of the embryonic form, the formation of the "smart Jiujiang" basic framework.

b. Development stage: comprehensively advancing and developing at a high speed. The integration of internal and external government resources to achieve efficient coordination of office and service. Create integrated government environment. The basic framework of "smart Jiujiang" is preliminarily constructed to support the integration, sharing and integration of information resources. Based on the "wisdom Jiujiang" command management center, launched panoramic management. To improve management, service and operation efficiency, the management model is changed from qualitative to quantitative and from abstract to concrete.

c. Perfect stage: continuous optimization, set benchmark. Establish a rational, complete and effective management and development system of information resources. Realize intelligent early warning and automatic response in key fields such as management. Overall upgrading of public management and service of water, and promote the transformation and upgrading of the city's industry. Build a benchmark for domestic smart city construction.

\section{Implementation Process}

The smart Jiujiang construction needs to gather all the forces and mobilize the enthusiasm of all parties to work together to promote the development of the smart city. On the one hand, the 
construction of financial funds for infrastructure, command centers, data centers, public management platform, public service platform investment for increase the wisdom of Jiujiang. On the other hand, we should actively attract social funds to participate in the construction of smart cities. Relax the relevant policies and increase the integration of government funds and social funds. Actively create a high degree of cohesion between government funds and social funds to promote the rapid development of "wisdom Jiujiang".

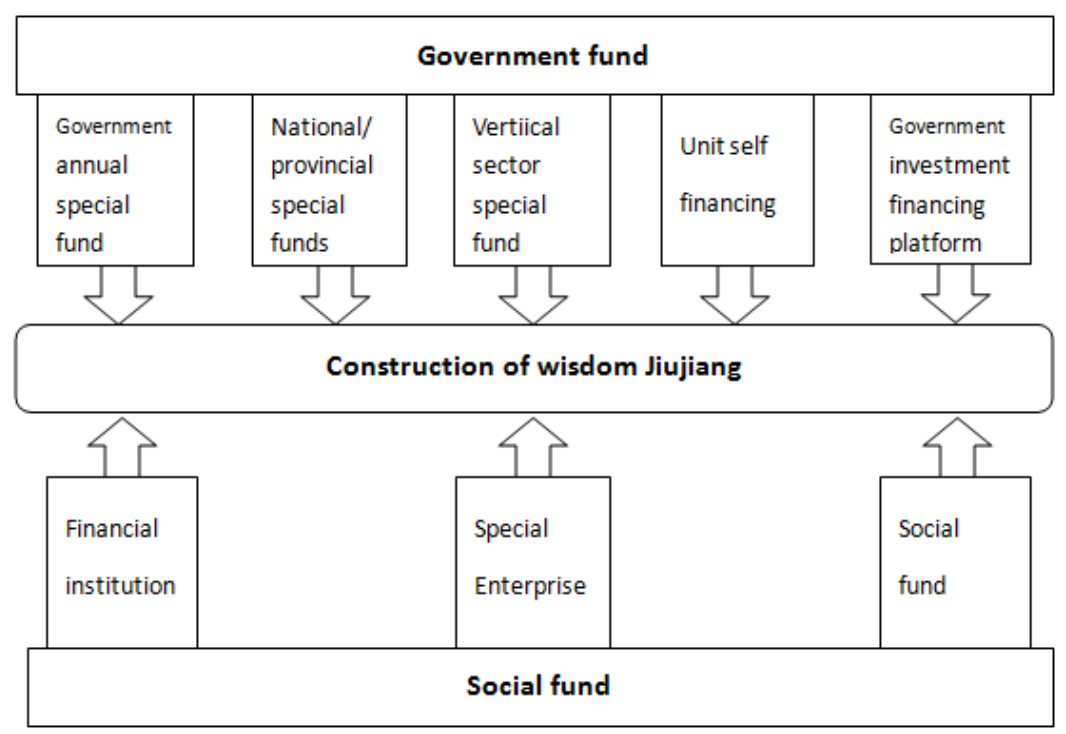

Fig.1 Smart Jiujiang project funding sources

The sole model is that the wisdom project entirely by the government investment in the construction and promotion. Ownership of the property is vested in the government after the completion of the construction. Specific projects and operations can be directly held by the government or outsourced to operators or social resources. Mainly suitable for government investment, involving public security, administration and other fields. Early investment, involving more government departments, and the latter can not bring commercial value of the project. Such as city emergency command system.

\section{Conclusions}

The implementation of Internet driven strategy and create future oriented smart city, Jiujiang is an important way to create "one of the province's green, dual core rise of the Yangtze River economic belt is an important center city, the world famous landscape and cultural city and tourist resort. It is an important measure to adapt to the revolution of information technology and accelerate the development of information technology and new industrialization, urbanization, agricultural modernization and green integration. Carrying out the construction of "wisdom Jiujiang" is the promotion of science and technology development, and also the inevitable development of the times.

\section{Acknowledgements}

Thanks for the support project: the Science and Technology Program of Jiangxi Province (20161BBA10034). 


\section{References}

[1] Ding Ge yuan, Li Zhenjiang, Zheng Hong Yun. Research of smart city application architecture [J]. Microcomputer \& Its Applications, 22(2013):123-126

[2] Xu Qin, System of Environment Monitoring Based on Internet of Things, International Conference on Applied Sciences Engineering and Technology (Qingdao,China,ICASET2014), p.664-667.

[3] Feng Lu, Zhao Jia yin, Guo Le Shen. The Construction about Intellectual Service Systems of Smart City [J].Journal of Beijing City University, 1(2014): 119-120

[4] Hu Ming Yuan. Key Technologies for Smart City Information System [D](Wuhan University, china 2014)

[5] Xiao Ru Fei. Research on Local Government Behavior in the Construction of Smart City[D]( Fujian Normal University, China 2014)

[6] Xu Qin, Wang Ying, Design of Explosive Production Information and Managing System Based on Internet of Things, International Conference on Control Automation and Robotie (Singapore,Singapore,ICCAR2015), p.173-176.

[7] LiLi, Luo Ling Jun, Hu Xu Wei. Research on the Path of Intelligent Chongqing Building [J], Geospatial Information, 12(2014):33-35. 